\title{
Socio-economic Predictors of Annual and Bi-annual Clinical Breast Examination among Women in Northeast Brazil
}

\section{Adriana Raquel Araújo Pereira Soares, Raissa de Oliveira Ramos and Mathias Weller*}

Post Graduate Program in Public Health, State University of Paraíba (UEPB), Campina Grande-Paraíba, Brazil

*Corresponding Author: Mathias Weller, Post Graduate Program in Public Health, State University of Paraíba (UEPB), Campina Grande-Paraíba, Brazil.
Received: May 03, 2021

Published: May 14, 2021

(C) All rights are reserved by Mathias Weller., et al.

\section{Abstract}

Introduction: There exist only few Brazilian studies about women's adherence on the clinical breast examination (CBE).

Objectives: This study of women in northeast Brazil addressed socio-economic variables besides physical activity and ancestry and their impact on performance of CBE.

Methods: Data were obtained by interviewing 307 women aged $\geq 40$ years old. All interviews were performed in a public health center of Campina Grande, state of Paraíba, Northeast Brazil. Multinomial logistic regression analysis was applied to determine odds ratios (ORs) and confidence intervals (CI) of variables.

Results: Of the 307 women 140 performed CBE never or irregular, whereas 137 and 30 performed it each year, respectively each second year. Women who used exclusively public health service centers had a 2.0 - fold (OR $=0.495 ; 95 \%$ CI: 0.28 - 0.74) decreased chance of annual CBE performance, compared to those ones who used public and private services $(p=0.006)$. In a model of logistic regression analysis, low- income women had a 3.1-fold ( $\mathrm{OR}=0.321$; 95\%CI: $0.11-0.92)$ decreased chance to undergo CBE every year $(p=0.009$ ). Unemployed women had a 2.8- fold (OR = 0.360; 95\%CI: $0.15-0.88$ ) decreased chance of bi- annual CBE performance. Women who informed European ancestry had a 2.8 (95\% CI: 1.45 - 5.26) increased chance to perform CBE each year, compared to those ones who informed African or mixed ancestry ( $p=0.005)$. Regular physical activity increased chance of annual CBE performance 1.9 (95\%CI: 1.10 - 3.29) times ( $\mathrm{p}=0.013)$.

Conclusion: Low income and unemployment decreased chance of regular CBE performance. Compared to African and mixed ancestry, informed European ancestry increased chance of regular CBE performance. Physical activity was also positively associated with regular CBE performance. Present data indicated that even among women sampled in the same public health service center regular CBE performance depended strongly on the socio- economic and ethnic background of women.

Keywords: Breast Cancer; Clinical Breast Examination; Prevention Behaviour

\section{Introduction}

According to the World Health Organization (WHO) in 2018 an estimated number of 2,088,849 new breast cancer cases contributed to $11.6 \%$ of all cancer deaths worldwide [1]. With a slope of
1.48 per 100,000 women the mortality trend between 1990 and 2015 in Latin America and the Caribbean was higher than in all other regions of the world [2]. In Brazil, with about 210 million inhabitants the largest country of Latin America, it was estimated that 66,280 new breast cancer cases will occur during each of the years 
from 2020 to 2022 [3]. Incidence of disease developed different in distinct regions of the country: In the more developed southern regions, including the two largest urban centers São Paulo and Rio de Janeiro, incidence remained stable over the last 15 years $[3,4]$. This is in contrast to the Northeast region, where the incidence between 2005 and 2020 increased from 27.23 to 44.29 new breast cancer cases per 100,000 women $[3,4]$.

There do not exist Brazilian prospective studies to evaluate the possible success of breast cancer screening methods and their potential to diminish breast cancer mortality by early detection of disease. Previous studies performed in Canada and Japan indicated an increased rate of early- detected breast tumors by the combination of mammography screening with CBE $[5,6]$. In the Japanese study the combined effect was stronger among women aged between 40 and 59 years compared to older women [5]. Of all 6333 cases in the Canadian study, the primary CBE -detected breast tumors had more aggressive features [6].

Like India and the other BRICS countries, Brazil has not implemented an organized breast cancer- screening program [7]. Mammography screening is performed in an opportunistic setting during the October Rose and depends widely on women's attitudes and possibilities of access. The clinical breast exam (CBE) instead, may stronger depend on women's frequency of visited public health care centers or private gynecologist and recommendations, respectively, performance of $\mathrm{CBE}$ by the corresponding medical stuff. According to the Brazilian ministry of health annual CBE is recommended for women aged 40 years or older [3].

As CBE is a low-cost test that has the potential to improve early detection of breast tumors previous studies focused on socio- economic variables that affect the frequency of performance [8-16]. Several Brazilian studies were performed in Southern regions of the country [17-19]. In a recent study performed in two health service centers of the Northeast region 187 out of 396 healthy women did perform CBE never or in an irregular manner [20]. This previous study did not include information about the type of health services used [20]. In the present study we asked in which way the use of private and public health services may affect the frequency of CBE performance and included also other socio- economic variables into the analysis.

\section{Methods}

Study population

The data sampling protocol was reviewed and approved by the Brazilian National Ethics Research Committee (CAAE plataforma Brasil: 63089416.0.0000.5187). Written informed consent was obtained from the participants, who were recruited from the Dr. Francisco Pinto de Oliveira public health service center located in Campina Grande, State of Paraíba, Brazil. This health service center offers ambulant treatment, including also vaccination, but no stationary treatment. The power sample calculation for the catchment area of the health care center indicated a minimum sample size of 96. Campina Grande is situated inland, about $120 \mathrm{~km}$ away from João Pessoa, the state capital on the Atlantic coast. With about 400,000 inhabitants, it is the second largest urban center of Paraíba. The state of Paraíba has like other regions of Northeast Brazil, a mixed population background, of African, European and Indigenous ancestry. The project was explained either individually or to small groups of two to five. The selection of eligible women and the interviews were carried out in the morning, in the waiting room of the health service center. Women were eligible if they were 40 years or older and if they did not have any type of breast cancer or any other chronic disease. The aim was to interview all eligible women in the waiting room during one morning with only one restriction: Data collection from more than two women who were related was avoided by including only one individual from each family. Most of the interviewed women accompanied children who had to be vaccinated while others had viral infections with symptoms of coughing, sneezing or gastro-intestinal nature.

Sampling was performed between May and December of 2019. This study period also included the "October Rose" month in which women were invited to participate in the public breast cancerscreening program. Communication with women and subsequent sampling were facilitated by public advertisements in favor of the public screening programs, which occurred during this month.

Sampling and questionnaires

Data about socio-demographic characteristics, CBE, and the sources of information about the prevention of breast cancer were obtained through face-to-face interviews with 307 women. All interviews were conducted by one of the authors using a questionnaire to which participants had to respond verbally. Data about

Citation: Mathias Weller., et al. "Socio-economic Predictors of Annual and Bi-annual Clinical Breast Examination among Women in Northeast Brazil". Acta Scientific Women's Health 3.6 (2021): 56-65. 
their knowledge of risk factors and symptoms of breast cancer were obtained by their completion of a second, self-administered questionnaire. The questionnaires were based on ones that had been developed and applied in previous studies [20,21].

Of all 307 women, 118 never attended CBE, whereas 22 attended it occasionally. These 140 (45.6\% of the study group) women were defined as the group of "Never or irregular" CBE attendees. The basic education level was defined as $\leq 8$ years of basic school education. Middle and high education levels were defined as between 8 - 12 years and above 12 years, respectively. Minimum wage and multiples thereof were used to define income. This is a popular and well-known method used to define economic level among lowand middle-class subjects. Minimum wage or less was defined as "low" income, whereas income equivalent to two and more times the minimum wage was defined as "high" income. The minimum wage in 2019 was R $\$ 998.00 /$ month (US\$237.60/month; $23^{\text {rd }}$ January 2020). A regular work out of the own household was defined as employment. Information about ancestry was obtained by selfclassification. Women choose between European, African or any type of mixed ancestry. Women were asked if a first-degree relative had breast or any other type of cancer. Participation in regular physical activity was defined as engaging in mild to moderate and/ or vigorous physical activity at the recommended levels of $\geq 150$ minutes and $\geq 75$ minutes per week, respectively [22]. When asked about the type of physical activity they engaged in, most women mentioned daily walks. Furthermore, hydrogymnastics and gymnastics in an academy were also often cited.

Knowledge about risk factors and symptoms of breast cancer

To assess their knowledge of risk factors, preventive behaviors, and symptoms of breast cancer, women were encouraged to tick a box for each factor they recognized out of the 33 potential risk factors, seven prevention behaviors and 22. Risk factors were related to lifestyle, reproduction, and family history. To enhance the assessment of participants' knowledge of risk factors and to lower the incidence of ticking boxes without reflection, 16 additional non-risk factors were included in the questionnaire among the 17 true risk factors. Similarly, among the nine true symptoms, 13 nonsymptoms were additionally included. This method was successfully applied in a previous study [21].

Regarding the questions related to knowledge, each factor correctly identified was assigned a score of 1 (known), while a factor incorrectly identified was assigned a score of 0 (unknown). The total score for each participant was determined as the sum of factors and correctly identified knowledge. The maximum possible score was 62 . The mean and median scores were $37.69(\mathrm{SD}=4.58)$ and 38.00 , respectively. The minimum and maximum scores obtained were 21 and 53, respectively. Quartiles were used to categorize knowledge; $\leq 34$ points ( $25 \%$ quartile) was defined as "low"; > 34 and $\leq 38$ (50\% quartile) was defined as "basic"; > 38 and $\leq 41$ points (75\% quartile) was defined as "middle" and $>41$ points (100\% quartile) was defined as "high".

\section{Statistical analysis}

All statistical analyses were performed using the SPSS STATISTICS $^{\text {TM }}$ software (SPPS; IBM company; version 24). The t-test was applied to compare continuous variables. ANOVA was used to compare more than two groups of continuous variables. Pearson's chi-square $\left(\chi^{2}\right)$ test was used to analyze categorical variables. To quantify associations among variables and CBE attendance, nominal logistic regression analysis was applied. Data of women who did not attend CBE served as the reference group. Results were presented as adjusted odd ratios (OR), 95\% confidence interval (CI) and p-value of likelihood ratio tests. Significant univariate regression analysis variables were used for regression modeling with multiple adjusted variables. Variables with significance levels less than 0.2 in the univariate analysis were included in the model. Then, variables with significance level less than 0.05 were kept in the model. Backward selection was used when significant variables were selected. The final model was tested for fitness using the likelihood ratio test.

\section{Results}

Of all 172 women aged between 40 and 49 years, 90 (52.3\%) performed CBE never or irregularly, whereas of the 91 and 44 women aged between 50 and 59 years, respectively $\geq 60$ years, a majority of 42 (46.2\%) and 29 (65.9\%) women performed it annually ( $\mathrm{p}=0.016$; Table 1). Descriptive statistical analysis indicated furthermore that the variables education level, income, employment status, ancestry, family history of cancer, physical activity, the type of health service used and the frequency of health service visit were heterogeneously distributed among women who performed CBE never or irregularly, respectively, annually and bi- annually (Table 1). 
Socio-economic Predictors of Annual and Bi-annual Clinical Breast Examination among Women in Northeast Brazil

\begin{tabular}{|c|c|c|c|c|}
\hline & Never or Irregular & Each year & Each second years & p-value \\
\hline \multicolumn{5}{|c|}{ Age } \\
\hline Mean age & $47.9(\mathrm{SD}=7.6)$ & $51.4(\mathrm{SD}=9.4)$ & $51.3(\mathrm{SD}=7.8)$ & 0.018 \\
\hline $40-49$ years & $90(52.3 \%)$ & $66(38.4 \%)$ & $16(9.3 \%)$ & \multirow[t]{3}{*}{0.016} \\
\hline $50-59$ years & $39(42.9 \%)$ & $42(46.2 \%)$ & $10(11.0 \%)$ & \\
\hline$\geq 60$ years & $11(25.0 \%)$ & $29(65.9 \%)$ & $4(9.1 \%)$ & \\
\hline \multicolumn{5}{|c|}{ Education level } \\
\hline Basic & $79(54.5 \%)$ & $51(35.2 \%)$ & $15(10.3 \%)$ & \multirow[t]{3}{*}{0.023} \\
\hline Middle & $47(39.2 \%)$ & $61(50.8 \%)$ & $12(10.0 \%)$ & \\
\hline High & $14(33.3 \%)$ & $25(59.5 \%)$ & $3(7.1 \%)$ & \\
\hline \multicolumn{5}{|c|}{ Income } \\
\hline Low & $120(53.1 \%)$ & $84(37.2 \%)$ & $22(9.7 \%)$ & \multirow[t]{3}{*}{$<0.001$} \\
\hline Middle & $14(25.5 \%)$ & $36(65.5 \%)$ & $5(9.1 \%)$ & \\
\hline High & $6(23.1 \%)$ & $17(65.4 \%)$ & $3(11.5 \%)$ & \\
\hline \multicolumn{5}{|c|}{ Employment } \\
\hline No & $99(52.7 \%)$ & $75(39.9 \%)$ & $14(7.4 \%)$ & \multirow[t]{2}{*}{0.005} \\
\hline Yes & $41(34.5 \%)$ & $62(52.1 \%)$ & $16(13.4 \%)$ & \\
\hline \multicolumn{5}{|c|}{ Ancestry } \\
\hline European & $21(26.9 \%)$ & $47(60.3 \%)$ & $10(12.8 \%)$ & \multirow[t]{2}{*}{0.001} \\
\hline Other one & $119(52.0 \%)$ & $90(39.3 \%)$ & $20(8.7 \%)$ & \\
\hline \multicolumn{5}{|c|}{ Civil state } \\
\hline No stable union & $59(43.1 \%)$ & $64(46.7 \%)$ & $14(10.2 \%)$ & \multirow[t]{2}{*}{0.725} \\
\hline Stable union & $81(47.6 \%)$ & $73(42.9 \%)$ & $16(9.4 \%)$ & \\
\hline \multicolumn{5}{|c|}{ Religion } \\
\hline Catholic & $86(45.7 \%)$ & $88(46.8 \%)$ & $14(7.4 \%)$ & \multirow[t]{2}{*}{0.202} \\
\hline Not catholic & $54(45.4 \%)$ & $49(41.2 \%)$ & $16(13.4 \%)$ & \\
\hline \multicolumn{5}{|c|}{ Family history of breast cancer } \\
\hline Yes & $37(46.3 \%)$ & $30(37.5 \%)$ & $13(16.3 \%)$ & \multirow[t]{2}{*}{0.053} \\
\hline No & $103(45.4 \%)$ & $107(47.1 \%)$ & $17(7.5 \%)$ & \\
\hline \multicolumn{5}{|c|}{ Family history of cancer } \\
\hline Yes & $72(39.8 \%)$ & $87(48.1 \%)$ & $22(12.2 \%)$ & \multirow[t]{2}{*}{0.030} \\
\hline No & $68(54.0 \%)$ & $50(39.7 \%)$ & $8(6.3 \%)$ & \\
\hline \multicolumn{5}{|c|}{ Physical activity } \\
\hline Yes & $45(35.7 \%)$ & $73(57.9 \%)$ & $8(6.3 \%)$ & \multirow[t]{2}{*}{$<0.001$} \\
\hline No & $95(52.5 \%)$ & $64(35.4 \%)$ & $22(12.2 \%)$ & \\
\hline \multicolumn{5}{|c|}{ Type of health service used } \\
\hline Only public & $90(53.6 \%)$ & $62(36.9 \%)$ & $16(9.5 \%)$ & \multirow[t]{2}{*}{0.006} \\
\hline Public and private & $50(36.0 \%)$ & $75(54.0 \%)$ & $14(10.1 \%)$ & \\
\hline \multicolumn{5}{|c|}{ Frequency of health service visit } \\
\hline$\leq 6$ month & $103(53.9 \%)$ & $73(38.2 \%)$ & $15(7.9 \%)$ & \multirow[t]{2}{*}{0.001} \\
\hline Annually & $37(31.9 \%)$ & $64(55.2 \%)$ & $15(12.9 \%)$ & \\
\hline
\end{tabular}

Table 1: Socio economic characteristics, family history of cancer and information about health service use of women, who performed CBE never, or irregular $(\mathrm{N}=140)$, during each year $(\mathrm{N}=137)$ respectively, each second year $(\mathrm{N}=30)$. 
Data indicated a direct association between performance of CBE and mammography screening: The chance of women who performed annual CBE also to perform annual mammography screening was about 8.3-fold (95\%CI: 4.53 - 15.16) increased compared to those women who performed CBE never or irregularly; Furthermore, those women who performed the CBE in each second year had also a 4.8- fold (95\%CI: 1.86 - 12.3) increased chance of bi-annual mammography screening, but a decreased chance to perform it annually $(\mathrm{p}<0.005)$.

Basic education level, low income and unemployment decreased chance of regular CBE performance in univariate regression analysis (Table 2). In contrast to African or mixed ancestry, European ancestry was associated with a 3.0 (95\%CI: $1.65-5.30)$ and 2.8 (95\%CI: 1.16 - 6.90) times increased chance of annual and bi-annual CBE performance ( $p<0.001$; Table 2). Compared to women with European ancestry, the chance of women with African or mixed ancestry to have a low or middle income was 3.2-fold (95\%CI: 1.39 - 7.29) and 4.0- fold (95\%CI: 1.45 - 11.0) higher than having a high income ( $p=0.015)$. Similar, African and mixed ancestry was associated with a 2.4- fold (95\%CI: 1.1 - 5.0) increased chance of low educational level $(p=0,076)$. Family history of cancer and physical activity also significantly increased chance of CBE performance, whereas family history of breast cancer had borderline significance in univariate analysis (Table 2).

\begin{tabular}{|c|c|c|c|c|}
\hline & \multirow[t]{2}{*}{ N (\%) } & \multicolumn{2}{|c|}{ OR ${ }_{\text {CRUDE }}(95 \% \mathrm{CI})$} & \multirow[t]{2}{*}{$\mathbf{P}$} \\
\hline & & Each year $(N=137)$ & Each second year $(\mathrm{N}=30)$ & \\
\hline \multicolumn{5}{|c|}{ Education level } \\
\hline Basic & $145(47.2 \%)$ & $0.362 *(0.17-0.76)$ & $0.886(0.23-3.47)$ & \multirow[t]{3}{*}{0.022} \\
\hline Middle & $120(39.1 \%)$ & $0.727(0.34-1.55)$ & $1.191(0.29-4.83)$ & \\
\hline High & $42(13.7 \%)$ & \multicolumn{2}{|c|}{ Ref. } & \\
\hline \multicolumn{4}{|c|}{ Income } & \\
\hline Low & $226(73.6 \%)$ & $0.247 *(0.09-0.65)$ & $0.367(0.09-1.58)$ & \multirow[t]{3}{*}{$<0.001$} \\
\hline Middle & $55(17.9 \%)$ & $0.908(0.30-2.77)$ & $0.714(0.13-4.00)$ & \\
\hline High & $26(8.5 \%)$ & \multicolumn{2}{|c|}{ Ref. } & \\
\hline \multicolumn{5}{|c|}{ Employment } \\
\hline No & $188(61.2 \%)$ & $0.501 *(0.31-0.82)$ & $0.362 *(0.16-0.81)$ & \multirow[t]{2}{*}{0.005} \\
\hline Yes & $119(38.8 \%)$ & \multicolumn{2}{|c|}{ Ref. } & \\
\hline \multicolumn{5}{|c|}{ Ancestry } \\
\hline European & $78(25.4 \%)$ & $2.959 *(1.65-5.30)$ & $2.833^{*}(1.16-6.90)$ & \multirow[t]{2}{*}{$<0.001$} \\
\hline Other one & $229(74.6 \%)$ & \multicolumn{2}{|c|}{ Ref. } & \\
\hline \multicolumn{5}{|c|}{ Civil state } \\
\hline No stable union & $137(44.6 \%)$ & $1.204(0.75-1.94)$ & $1.201(0.54-2.65)$ & \multirow[t]{2}{*}{0.725} \\
\hline Stable union & $170(55.4 \%)$ & & ef. & \\
\hline \multicolumn{5}{|c|}{ Religion } \\
\hline Catholic & $188(61.2 \%)$ & $1.128(0.69-1.84)$ & $0.549(0.25-1.22)$ & \multirow[t]{2}{*}{0.209} \\
\hline Not catholic & $119(38.8 \%)$ & & ef. & \\
\hline \multicolumn{5}{|c|}{ Family history of breast cancer } \\
\hline Yes & $80(26.1 \%)$ & $0.781(0.45-1.36)$ & $2.129(0.94-4.80)$ & \multirow[t]{2}{*}{0.065} \\
\hline No & $227(73.9 \%)$ & \multicolumn{2}{|c|}{ Ref. } & \\
\hline
\end{tabular}

Citation: Mathias Weller., et al. "Socio-economic Predictors of Annual and Bi-annual Clinical Breast Examination among Women in Northeast Brazil". Acta Scientific Women's Health 3.6 (2021): 56-65. 
Socio-economic Predictors of Annual and Bi-annual Clinical Breast Examination among Women in Northeast Brazil

\begin{tabular}{|c|c|c|c|c|}
\hline \multicolumn{5}{|c|}{ Family history of cancer } \\
\hline Yes & $181(59.0 \%)$ & $1.643^{*}(1.02-2.66)$ & $2.597 *(1.08-6.23)$ & \multirow[t]{2}{*}{0.028} \\
\hline No & $126(41.0 \%)$ & \multicolumn{2}{|c|}{ Ref. } & \\
\hline \multicolumn{5}{|c|}{ Physical activity } \\
\hline Yes & $126(41.0 \%)$ & $2.408 *(1.48-3.92)$ & $0.768(0.32-1.86)$ & \multirow[t]{2}{*}{$<0.001$} \\
\hline No & $181(59.0 \%)$ & & & \\
\hline \multicolumn{5}{|c|}{ Type of health service used } \\
\hline Only public & $168(54.7 \%)$ & $0.495^{*}(0.28-0.74)$ & $0.635(0.29-1.4)$ & \multirow[t]{2}{*}{0.006} \\
\hline Public and private & $139(45.3 \%)$ & & & \\
\hline \multicolumn{5}{|c|}{ Frequency of health service visit } \\
\hline$\leq 6$ month & $191(62.2 \%)$ & $0.410 *(0.25-0.68)$ & $0.359 *(0.16-0.81)$ & \multirow[t]{2}{*}{0.001} \\
\hline Annually & $116(37.8 \%)$ & & & \\
\hline \multicolumn{5}{|c|}{ Smoking } \\
\hline Yes & $21(6.8 \%)$ & $0.825(0.33-2.06)$ & $0.404(0.05-3.26)$ & \multirow[t]{2}{*}{0.625} \\
\hline No & $286(93.2 \%)$ & & & \\
\hline \multicolumn{5}{|c|}{ Consumption of alcohol } \\
\hline Yes & $47(15.3 \%)$ & $1.695(0.87-3.29)$ & $1.113(0.35-3.58)$ & \multirow[t]{2}{*}{0.275} \\
\hline No & $260(84.7 \%)$ & & & \\
\hline \multicolumn{5}{|c|}{ Knowledge about risk factors and symptoms of disease } \\
\hline Low & $77(25.1 \%)$ & $1.360(0.66-2.79)$ & $2.476(0.59-10.35)$ & 0.339 \\
\hline Basic & $92(30.0 \%)$ & $0.711(0.36-1.42)$ & $1.660(0.41-6.67)$ & \\
\hline Middle & $81(26.4 \%)$ & $0.762(0.38-1.55)$ & $2.222(0.56-8.85)$ & \\
\hline High & $57(18.6 \%)$ & \multicolumn{2}{|c|}{ Ref. } & \\
\hline
\end{tabular}

Table 2: Regression analysis of each single variable is shown as odds ratio $\left(\mathrm{OR}_{\mathrm{CRUDE}}\right)$ and confidence interval (95\%CI) for women who performed CBE each year $(\mathrm{N}=137)$ and each second year $(\mathrm{N}=30)$. Women who did not perform CBE $(\mathrm{N}=140)$ served as reference group.

$$
* \mathrm{p}<0.050 \text {. }
$$

Women who used exclusively public health services had a 2.0 $(\mathrm{OR}=0.495 ; 95 \% \mathrm{CI}: 0.28$ - 0.74) times decreased chance of annual CBE performance, compared to those ones who used public and private services ( $p=0.006$; Table 2 ). Paradoxically those women, who visited a health service in a six- month period, or more frequently, had a 2.4-fold (OR = 0.410; 95\%CI: 0.25 - 0.68) and 2.8-fold $(\mathrm{OR}=0.359 ; 95 \% \mathrm{CI}: 0.16-0.81)$ decreased chance of annual and bi-annual CBE performance compared to those ones who visited it annually ( $p=0.001$; Table 2). The frequency of health service visit was not age dependent $(\mathrm{p}=0.306)$. Instead, exactly those women who used exclusively public health services, had 1.7- fold (95\%CI: 1.07 - 2.71) increased chance to visit a health service in a six- month period, or more frequently $(p=0.025)$.
To identify independent variables a model of multivariate logistic regression analysis was formed (Table 3 ). In this model low income decreased the chance of annual CBE performance 3.1 (OR $=0.321 ; 95 \%$ CI: $0.11-0.92)$ times $(\mathrm{p}=0.009$; Table 3$)$. Having no employment, decreased women's chance bi-annual CBE performance $2.8(\mathrm{OR}=0.360$; 95\%CI: 0.15 - 0.88) times ( $\mathrm{p}=0.048$; Table 3 ). European ancestry was associated with a 2.8-fold (95\%CI: 1.45 - 5.26) increased chance of annual CBE performance compared to women with an African or mixed background ( $p=0.005$; Table 3). Family history had a weak significant contribution to the model ( $p$ $=0.046$; Table 3). Women who performed physical activity had a 1.9 (95\%CI: 1.10 - 3.29) times increased chance of annual CBE performance $(p=0.013$; Table 3$)$. 


\begin{tabular}{|c|c|c|c|c|}
\hline & & Each year $(N=137)$ & Each second year $(\mathrm{N}=30)$ & \\
\hline & N (\%) & \multicolumn{2}{|c|}{$\mathrm{OR}_{\text {ADJUSTED }}(95 \% \mathrm{CI})$} & $\mathbf{P}$ \\
\hline \multicolumn{4}{|c|}{ Income } & \\
\hline Low & $226(73.6 \%)$ & $0.321 *(0.11-0.92)$ & $0.670(0.14-3.33)$ & \multirow[t]{3}{*}{0.009} \\
\hline Middle & $55(17.9 \%)$ & $0.991(0.30-3.32)$ & $0.970(0.15-6.24)$ & \\
\hline High & $26(8.5 \%)$ & \multicolumn{2}{|c|}{ Ref. } & \\
\hline \multicolumn{5}{|c|}{ Employment } \\
\hline No & $188(61.2 \%)$ & $0.613(0.35-1.01)$ & $0.360 *(0.15-0.88)$ & \multirow[t]{2}{*}{0.048} \\
\hline Yes & $119(38.8 \%)$ & \multicolumn{2}{|c|}{ Ref. } & \\
\hline \multicolumn{5}{|c|}{ Ancestry } \\
\hline European & $78(25.4 \%)$ & $2.761 *(1.45-5.26)$ & $2.414(0.93-6.28)$ & \multirow[t]{2}{*}{0.005} \\
\hline Other one & $229(74.6 \%)$ & \multicolumn{2}{|c|}{ Ref. } & \\
\hline \multicolumn{5}{|c|}{ Physical activity } \\
\hline Yes & $126(41.0 \%)$ & $1.901 *(1.10-3.29)$ & $0.650(0.25-1.66)$ & \multirow[t]{2}{*}{0.013} \\
\hline No & $181(59.0 \%)$ & \multicolumn{2}{|c|}{ Ref. } & \\
\hline
\end{tabular}

Table 3: A model of logistic regression analysis adjusted for age, family history of breast cancer and the frequency of health service visit. Odds ratios $\left(\mathrm{OR}_{\mathrm{ADJUSTED}}\right)$ and confidence intervals $(95 \% \mathrm{CI})$ are shown for women who performed $\mathrm{CBE}$ each year $(\mathrm{N}=137)$ and each second year $(\mathrm{N}=30)$. Women who did not perform CBE, or performed it irregularly $(\mathrm{N}=140)$, served as reference group.

$$
* \mathrm{p}<0.050
$$

\section{Discussion and Conclusion}

The present study identified income, employment status and family history of breast cancer as independent variables that were associated with women's adherence on regular CBE performance. In the final model also ancestry and physical activity contributed to this model. To the best of our knowledge this is the first Brazilian study that attributed an important role of physical activity on CBE adherence.

In a previous study also performed in Northeast Brazil, 64 $(16.2 \%)$ and 187 (47.2\%) out of 396 women performed CBE never and sometimes [20]. In the present study these numbers were lower: Of all 307 women 118 (38.4\%) performed CBE never and $22(7.2 \%)$ performed it sometimes. Furthermore, in the previous study of Alves and colleagues (2019) the compared categories of women were different: Socio-demographic variables of all women who performed CBE regularly, annually or bi- annually were compared with those ones who performed it sometimes and never [20]. Sampling was partially performed in a public hospital among wom- en who visited patients, whereas the present sample embraced exclusively women who were interviewed in the same public health service center [20]. These findings indicate remarkable differences regarding CBE performance among women sampled in different health service centers. Additionally, present data also indicated that the frequency of regular CBE performance was higher among women who used both, public and private health services compared to those ones who used exclusively public ones.

Low income decreased chance of women's regular CBE performance. In agreement with this finding several previous studies performed in Malaysia and Brazil also associated low income with decreased chance of CBE performance [11,17-19]. Other studies in contrast, performed in India and the Philippines, associated low income with an increased chance of CBE performance $[8,9,13]$. Income as a decisive variable may highly depend on the context of other socio- demographic parameters. In a previous study performed in Northeast Brazil low education was an independent variable, but not income [20]. In the present study women with a low education level also had a decreased chance of CBE perfor- 
mance in univariate analysis. However, in the present study group income was more heterogeneously distributed among categories of CBE performance than education levels and consequently, also turned out to be more important.

Women who were employed had an increased chance of regular CBE performance compared to those ones who worked exclusively at home. In the final model of Alves and colleagues (2019) employment had borderline significance [20]. In another previous Brazilian study employment was not significantly associated with CBE performance [18]. Similar, in previous studies from India and Iran positive employment status also did not significantly contribute to women's adherence on regular CBE performance $[9,13,14]$. It remained unclear why in the present study group employment status represented a decisive variable.

Women who informed European ancestry had an increased chance of regular CBE performance compared to those ones who informed African or mixed ancestry. This finding was in agreement with previous Brazilian studies $[17,18]$. In the present study group informed African or mixed ancestry was also associated with low income and low educational level, compared to the group of women who informed European ancestry. Findings of the present and previous Brazilian studies point to differences of CBE adherence among women with a distinct ethnic background.

In the final model also physical activity was positively associated with regular CBE performance. This is the first Brazilian study that associated physical activity with regular CBE performance. Previous Brazilian database studies associated regular performance of physical activity with adherence on mammography screening [23,24]. Similar, studies performed in Lithuania and the USA revealed that the chances of ever attending mammography screening and attending it at minimum once within two years were higher among women who regularly performed physical activity $[25,26]$. Physical exercise is one attribute of a healthy lifestyle and may also be associated with other factors like avoiding smoking, alcohol abuse, and unhealthy dietary habits. This attitude may be positively associated with breast cancer prevention and therefore also increase chance of regular CBE. Present data indicated that regular performance of $\mathrm{CBE}$ was positively associated with regular mammography screening. As mammography screening in contrast to the CBE, is performed spontaneously, without any invitation this could mean that regular $\mathrm{CBE}$ performance positively influences women's choice to perform regular mammography screening. Alternatively, women's choice to adhere on mammography screening also could be influenced by recommendations of the medical stuff of the health service center that performs CBE.

It can also not be excluded that women who informed annual and bi- annual performance of CBE, erroneously also informed regular mammography screening for the same time intervals. Recall bias among the interviewed women cannot be excluded. As all 307 interviewed women visited the same health service center, the sample of the present study may neither be representative for women who use other health service centers nor for those ones who use private gynecologist. As women's performance of CBE depends highly on the medical stuff of the health service center, its frequency can reveal remarkable differences between different institutions. Another important limitation was that data it did not include information about women's health beliefs.

The present study indicated that low income and unemployment reduced chance of CBE performance. Women who informed European ancestry had an increased chance of regular CBE performance, indicating behavioral differences between ethnic groups. Physical activity also increased chance of CBE performance. In contrast to the other well- established predictors of regular CBE performance, physical activity so far was not identified in Brazilian literature as an important predictive factor. Future studies of women in northeast Brazil should include information about health beliefs and how these are associated with women's willingness to physical activity. More detailed information about CBE performance by medical stuff of the used health service center and recommendations about mammography screening should also be included.

\section{Acknowledgements}

We would like to thank all participating women of Campina Grande and supporting stuff of both public health care centers. This work was funded by the Brazilian "Coordenação de Aperfeiçoamento de Pessoal de Nível Superior (CAPES)". 


\section{Bibliography}

1. World Health Organization. "WHO report on cancer: setting priorities, investing wisely and providing care for all” (2020)?

2. Fitzmaurice C., et al. "Global, Regional, and National Cancer Incidence, Mortality, Years of Life Lost, Years Lived With Disability, and Disability-Adjusted Life-years for 32 Cancer Groups, 1990 to 2015. A Systematic Analysis for the Global Burden of Disease Study". JAMA Oncology 3.4 (2017): 524-548.

3. Instituto Nacional de Câncer (INCA). "Estimativa 2020: Incidência de câncer no Brasil" (2020).

4. Instituto Nacional de Câncer (INCA). "Estimativa 2005: Incidência de câncer no Brasil" (2005).

5. Ohta K., et al. "Is clinical breast examination effective in Japan? Consideration from the age-specific performance of breast cancer screening combining mammography with clinical breast examination". Breast Cancer 23.2 (2016): 183-189.

6. Provencher L., et al. "Is clinical breast examination important for breast cancer detection?" Current Oncology 23.4 (2016): e332-e339.

7. Basu P., et al. "A pragmatic approach to tackle the rising burden of breast cancer through prevention and early detection in countries 'in transition"'. Indian Journal of Medical Research 152 (2020): 343-355.

8. Pisani P., et al. "Outcome of screening by clinical examination of the breast in a trial in the Philippines". International Journal of Cancer 118.1 (2006): 149-154.

9. Dinshaw K., et al. "Determinants of Compliance in a Cluster Randomised Controlled Trial on Screening of Breast and Cervix Cancer in Mumbai, India”. Oncology 73.3-4 (2007): 145153.

10. Oluwatosin OA. “Assessment of women's risk factors for breast cancer and predictors of the practice of breast examination in two rural areas near Ibadan, Nigeria". Cancer Epidemiology 34.4 (2010): 425-428.
11. Parsa P and Kandiah M. "Predictors of Adherence to Clinical Breast Examination and Mammography Screening among Malaysian Women". Asian Pacific Journal of Cancer Prevention 11.3 (2010): 681-688.

12. Sankaranarayanan K., et al. "Clinical Breast Examination: Preliminary Results from a Cluster Randomized Controlled Trial in India". Journal of the National Cancer Institute 103.19 (2011): 1476-1480.

13. Frie KG., et al. "Determinants of Participation in a Breast Cancer Screening Trial in Trivandrum District, India". Asian Pacific Journal of Cancer Prevention 14.12 (2013): 7301-7307.

14. Tilaki KH and Auladi S. "Awareness, Attitude, and Practice of Breast Cancer Screening Women, and the Associated SocioDemographic Characteristics, in Northern Iran". Iranian Journal of Cancer Prevention 8.4 (2015): e3429.

15. Ghahramanian A., et al. "Relationships of Fear of Breast Cancer and Fatalism with Screening Behavior in Women Referred to Health Centers of Tabriz in Iran". Asian Pacific Journal of Cancer Prevention 17.9 (2016): 4427-4432.

16. Lee HY., et al. "Breast Cancer Screening Disparity among Korean American Immigrant Women in Midwest". Asian Pacific Journal of Cancer Prevention 18.10 (2017): 2663-2667.

17. Dias-da-Costa JS., et al. "Inequalities in clinical breast examination in São Leopoldo, Rio Grande do Sul, Brazil". Cadernos de Saúde Pública 23.7 (2007): 1603-1612.

18. Amorim VMSL., et al. "Factors associated with lack of mammograms and clinical breast examination by women: a population- based in Campinas, São Paulo State, Brazil". Cadernos de Saúde Pública 24.11 (2008): 2623-2632.

19. Borges ZS., et al. "Clinical breast examination and mammography: Inequalities in Southern and Northeast Brazilian regions". Revista Brasileira de Epidemiologia 19.1 (2016): 1-13.

20. Alves SAV., et al. "Impact of Education and Health Treatment Options on Performance of Clinical Breast Examination". Acta Scientific Women's Health 1.6 (2019): 02-09.

Citation: Mathias Weller., et al. "Socio-economic Predictors of Annual and Bi-annual Clinical Breast Examination among Women in Northeast Brazil". Acta Scientific Women's Health 3.6 (2021): 56-65. 
21. Freitas AGQ and Weller M. "Knowledge about Risk Factors for Breast Cancer and Having a Close Relative with Cancer Affect the Frequency of Breast Self-Examination Performance". Asian Pacific Journal of Cancer Prevention 17.4 (2016): 2075-2081.

22. Runowicz CD., et al. "American cancer Society/American Society of clinical oncology breast cancer survivorship care guideline". Journal of Clinical Oncology 34.6 (2016): 611-635.

23. Barbosa YC., et al. "Factors associated with lack of mammography: National Health Survey, 2013". Revista Brasileira de Epidemiologia 22 (2019): E190069.

24. Filha MMT., et al. "Regional and social inequalities in the performance of Pap test and screening mammography and their correlation with lifestyle: Brazilian national health survey". International Journal for Equity in Health 15 (2016): 136.

25. Kriaucioniene V and Petkeviciene J. "Predictors and Trend in Attendance for Breast Cancer Screening in Lithuania, 20062014". International Journal of Environmental Research and Public Health 16 (2019): 4535.

26. Progovac AM., et al. "Optimism may moderate screening mammogram frequency in Medicare”. Medicine 98.24 (2019): e15869.

\section{Volume 3 Issue 6 June 2021}

\section{(c) All rights are reserved by Mathias Weller., et al.}

